\title{
ESTUDO MORFOLÓGICO E QUANTITATIVO DOS HEMÓCITOS EM LARVAS DE DIATRAEA SACCHARALIS (FABRICIUS) (LEPIDOPTERA, PYRALIDAE)
}

\author{
Maria T. Siqueira Bombonato ${ }^{1}$ \\ Elisa A. Gregório ${ }^{2}$
}

\begin{abstract}
MORPHOLOGICAL AND QUANTIIATIVE: STUIIES OH THE: HEMOCYTES IN LARVAE OF DIATRAEA SACCHARALIS (FABRICIUS) (LePIDOPTIRA, PYrAL JDAE). Hemocytes of Diatraea saccharalis larvae aging from 13 to 26 days old were morphological and quantitatively characterized by phase contrast microscopy. Six hemocyte types were described and identified as: prohemocytes (PR). plasmatocytes (PL), granulocytes (GR), oenocytoides (OE), spherulocytes (SP) and verm cells (VE). The total hemocyte counts showed no significant difference in the number of these cells along the normal development of the larvae. However, the relative number of different circulating hemocyte types fluctuated, and it could be expressed as: $\mathrm{PL}>\mathrm{GR}>\mathrm{SP}>\mathrm{PR}>\mathrm{VE}>\mathrm{OE}$ in larvae up to 14 days old: and as: $\mathrm{GR}>\mathrm{SP}>\mathrm{PL}>$ $\mathrm{VE}>\mathrm{OE}>\mathrm{PR}$ in those older than 24 days.

KEY WORDS. Lepidoptera, Pyralidae, Diatraea saccharalis, total hemocyte count, differential hemocyte count, hemolymph
\end{abstract}

Nos últimos anos, excelentes revisões e estudos comparativos da morfologia dos hemócitos de insetos foram realizados (GUPTA 1979; RATCLIFFE \& ROWLEY 1979; Gupta 1985, RAtClifFe et al. 1985, ChiAng et al. 1988; Azambuja et al. 1991; KURIHARA et al. 1992; SAXENA 1992). Os autores estabeleceram tipos celulares básicos, que ocorrem em quase todos os insetos, e que são: prohemócito, plasmatócito, granulócito e oenocitóide. Formas adicionais, também foram reconhecidas: coagulócito, adipohemócito, esferulócito, podócito e vermiforme, encontradas somente em algumas das espécies estudadas (GUPTA 1979, 1985; GOTZ \& BOMAN 1985).

Os hemócitos desempenham funções essenciais para o desenvolvimento dos insetos. Estas células foram relacionadas com a coagulação da hemolinfa (BOHN 1986), estoque, metabolismo e distribuição de nutrientes e hormônios (WIGGLESWORTH 1959, 1979a; TAKEDA 1977; DE KORT \& GRANGER 1981), formação de tecido conjuntivo e membrana basal e remodelação de orgãos e tecidos durante 0 processo de muda (BEAUlaton 1968; WigGLESWOTH 1972, 1979a, 1979b; PERCY 1978; SECCO 1990) e principalmente, com os mecanismos de defesa contra

1) Departamento de Ciências Biológicas. Faculdade de Ciências. Universidade Estadual Paulista. Caixa Postal 473, 17033-360 Bauru, São Paulo, Brasil.

2) Departamento de Morfologia, Instituto de Biociências. Universidade Estadual Paulista. Caixa Postal 501, 18618-0)(0) Botucatu, São Paulo. Brasil. 
invasores da hemocele (ver revisões de RATCLIFFE \& ROWLEY 1979; GOTZ \& BOMAN 1985; RATCLIFFE et al. 1985).

Os hemócitos estão envolvidos direta ou indiretamente com a capacidade dos insetos de reagir contra a invasão de parasitas e patógenos, desencadeando uma série de reações de defesa celulares e/ou humorais (RATCLIFFE \& ROWLEY 1979; RATCliffe et al. 1985). No estudo do papel dos hemócitos nas reações de defesa, a caracterização destas células, ao nível de microscopia de contraste de fase e utilizando-se de preparações celulares in vivo, é de fundamental importância para uma melhor compreensão do comportamento das mesmas frente às diferentes condições experimentais.

A larva de Diatraea saccharalis (Fabricius, 1794) (Lepidoptera: Pyralidae), também conhecida como broca da cana-de açúcar, é uma praga da cultura canavieira. Além de afetar o desenvolvimento desta cultura, reduz significativamente o rendimento do aproveitamento da cana-de-açúcar, pela diminuição na pureza do caldo, inversão da sacarose e contaminação no processo de fermentação. Esta praga tem sido controlada biologicamente através da liberação maciça de parasitóides nas plantações. Pouco se conhece, entretanto, sobre os mecanismos pelos os quais estes parasitóides conseguem escapar das reações de defesa da broca da cana.

Dentro de um projeto amplo de estudo dos hemócitos e das reações de defesa de $D$. saccharalis contra diferentes patógenos, propôs-se caracterizar os hemócitos, do ponto de vista morfológico e quantitativo, em larvas normais de $D$. saccharalis, ao longo de seu desenvolvimento. Os resultados obtidos neste estudo servirão de subsídios para o entendimento do papel de cada uma destas células nas reações de defesa das larvas de $D$. saccharalis parasitadas.

\section{MATERIAL E MÉTODOS}

Os exemplares de larvas de $D$. saccharalis utilizados neste trabalho foram fornecidos pelo Laboratório de Controle de Pragas da Usina da Barra Açúcar e Álcool S.A. (Barra Bonita, São Paulo). As larvas foram cultivadas em tubos contendo dieta artificial (HENSEY \& HAMMOND 1968) e mantidas à temperatura de $25-27^{\circ} \mathrm{C}$ e umidade relativa de $70 \pm 10 \%$.

Hemolinfa de larvas com 13 a 26 dias de desenvolvimento foram analisadas dia a dia. Após rápida limpeza das larvas em água destilada e álcool 70\%, estas foram colocadas sobre gelo por cinco minutos, para facilitar sua manipulação. Através de incisão na região ventral, próxima à cabeça, obteve-se a gota de hemolinfa, que foi coletada com pipeta Pasteur e utilizada para análise em microscópio de contraste de fase.

Para caracterização dos tipos de hemócitos, gota de hemolinfa foi adicionada à gota de solução anticoagulante de inseto, preparada segundo LEONARD et al. (1985), com osmolaridade ajustada para $360 \mathrm{mOsKg}^{-1}$.

A contagem total de hemócitos foi realizada em hemolinfa não diluída, utilizando câmara de Neubauer modificada. Foram realizadas contagens em hemolinfa de 30 insetos/idade. Os valores obtidos foram submetidos à análise de 
variância e aplicado o Teste de Tukey, para a comparação das médias, de acordo com VIEIRA \& HOFFMAN (1989).

A contagem diferencial dos hemócitos foi realizada em preparações de gota de hemolinfa diluída na solução anticoagulante de inseto. Foram utilizados 10 insetos/idade, sendo que para cada inseto foram contadas 100 células, num total de 1000 células/idade. Aos valores obtidos foi aplicado o Teste de Hipótese, para a comparação de duas proporções (COSTA-NETO 1984).

\section{RESULTADOS}

\section{A) Análise Morfológica dos Hemócitos}

A hemolinfa de larvas de $D$. saccharalis apresentou seis tipos de hemócitos (Figs 1 a 11), identificados como: prohemócito, plasmatócito, granulócito, células vermiforme, esferulócito e oenocitóide.

Prohemócito (PR): célula pequena e arredondada, com núcleo grande e central, citoplasma escasso com pouca ou nenhuma inclusão reconhecível; o contorno do PR não mostrou projeções evidentes (Fig. 2). A relação núcleocitoplasmática era alta, com o núcleo ocupando cerca de 65 a $80 \%$ do total do volume celular.

Plasmatócito (PL): constituiu o grupo mais polimórfico, com tamanhos e formas bastante variáveis (Figs 1, 3-5). A maioria dos PL era arredondada ou ovalada, com núcleo central, citoplasma homogêneo e abundante sem projeções evidentes (Figs 3-5). Estas células podiam aderir e se espalhar sobre a superfície da lâmina histológica, o que permitia a formação de extensos processos citoplasmáticos, com concentração de organelas ao redor do núcleo (Figs 4 e 11).

Granulócito (GR): célula arredondada, com núcleo relativamente pequeno, redondo ou ovalado, geralmente central. O citoplasma apresentava grande quantidade de grânulos refringentes (Figs 1, 8 e 9). A membrana plasmática apresentava, caracteristicamente, longas projeções irregulares e agrupadas, que conferiam ao GR o aspecto de "polvo" (Figs 1 e 9). Observamos gotículas de lipídios em GR de larvas próximas à pupação (Fig. 10).

Célula vermiforme (VE): célula com núcleo geralmente pequeno e central. As VE não aderiam à superfície de vidro da lâmina, nem às outras células. $\mathrm{O}$ citoplasma era extenso e delgado, formando halo citoplasmático ao redor da região nuclear, que fazia protusão na superfície celular; durante a observação, o halo citoplasmático dobrava-se conferindo-lhe geralmente aspecto fusiforme (Fig. 6) e tornando difícil sua documentação.

Esferulócito (ES): célula arredondada ou elíptica, com tamanhos bastante variáveis (Figs 1, 3 e 10). Seu núcleo pequeno e excêntrico era, muitas vezes, camuflado pelas esférulas características, que preenchiam o citoplasma. O contorno do ES era bastante irregular devido às protuberâncias que as esferas citoplasmáticas faziam na superfície celular, conferindo-lhe o aspecto de amora (Figs 1, 3 e 10).

Oenocitóide (OE): era o maior dos hemócitos observado, geralmente 

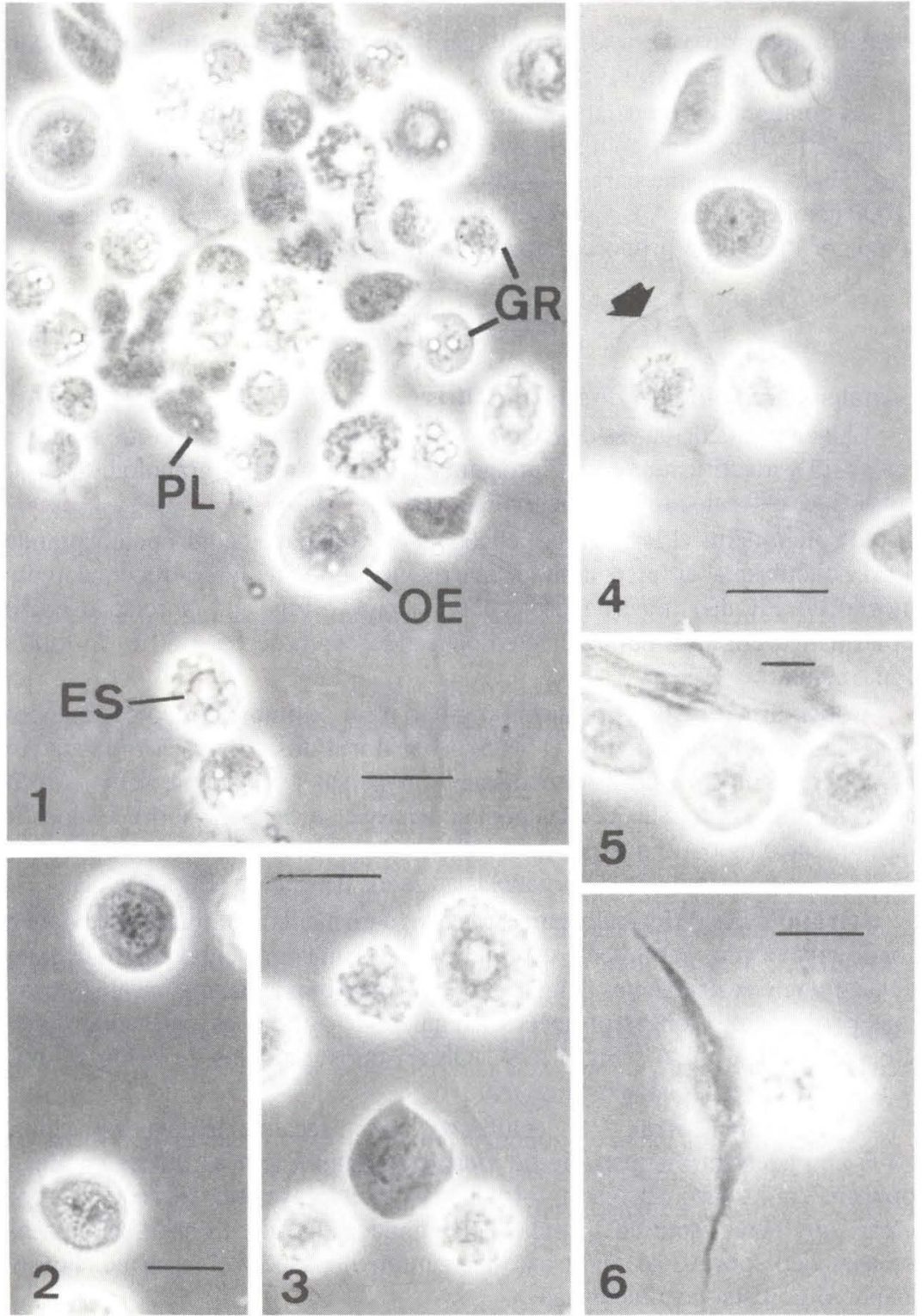

Figs 1-6. Hemócitos de larvas de D. saccharalis, (1) Aspecto geral dos hemócitos em larvas de 21 dias (barra $=50 \mu \mathrm{m}$ ); (2) PR em larvas de 15 dias (barra $=20 \mu \mathrm{m}$ ); (3) PL jovem e ES em larvas de 15 dias $($ barra $=50 \mu \mathrm{m})$; (4) PL e PL espalhado (seta) em larvas de 19 dias (barra $=50 \mu \mathrm{m})$; (5) PL em larvas de 23 dias (barra $=20 \mu \mathrm{m})$; (6) VE e ES em larvas de 15 dias $($ barra $=20 \mu \mathrm{m})$. Prohemócito $(\mathrm{PR})$, Plasmatócito $(\mathrm{PL})$, Granulócito $(\mathrm{GR})$, Esferulócito (ES), Oenocitóide (OE), Células Vermiformes (VE). 
arredondado ou ligeiramente ovalado; seu núcleo pequeno localizava-se central ou excentricamente (Figs 1 e 7). O citoplasma era bastante homogêneo, podendo apresentar pequenas granulações esparsas. O contorno celular era bastante regular e liso (Fig. 7).

\section{B) Análise Quantitativa dos Hemócitos}

A contagem total de hemócitos $(\mathrm{CTH})$ não mostrou variações significativas no número destas células, ao longo do desenvolvimento normal da $D$. saccharalis, no período compreendido de 13 a 25 dias (Tab. I). Em larvas de 13 dias, o número de hemócitos circulantes era de $166,48 \times 10^{5}$ células/ml de hemolinfa, enquanto que naquelas com 25 dias era de $167,23 \times 10^{5}$ células $/ \mathrm{ml}$. Já em larvas de 26 dias, a CTH alcançou um valor de $187,43 \times 10^{5}$ células $/ \mathrm{ml}$ de hemolinfa.

Tabela I. Contagem total de hemócitos (CTH) em hemolinfa de larvas de $D$. saccharalis com idade variando de 13 a 26 dias.

\begin{tabular}{lcc}
\hline Idade da larva (dias) & Número de hemócitos ${ }^{*}$ & Número de larvas \\
\hline 13 & $166,48 \pm 5,45$ & 30 \\
14 & $169,93 \pm 5,66$ & 30 \\
15 & $166,40 \pm 5,98$ & 30 \\
16 & $168,20 \pm 4,41$ & 30 \\
17 & $159,45 \pm 4,38$ & 30 \\
18 & $174,79 \pm 5,29$ & 30 \\
19 & $159,66 \pm 5,42$ & 30 \\
20 & $165,25 \pm 5,07$ & 30 \\
21 & $164,46 \pm 4,71$ & 30 \\
22 & $166,24 \pm 7,66$ & 30 \\
23 & $173,14 \pm 4,21$ & 30 \\
24 & $168,48 \pm 3,85$ & 30 \\
25 & $167,23 \pm 3,25$ & 30 \\
26 & $187,43 \pm 4,40$ & 30 \\
\hline
\end{tabular}

* Médias e erros padrão do número total de hemócitos, expressos como número de células $\times 10^{5} / \mathrm{ml}$ de hemolinfa.

Os resultados obtidos através da contagem diferencial de hemócitos ( $\mathrm{CDH})$ em larvas de $D$. saccharalis, no período de 13 a 26 dias de idade, estão expressos na tabela II. Os OE e VE foram as células menos encontradas em larvas com até 15 dias, apresentando poucas variações ao longo do período estudado. Os PR representaram $10,57 \%$ dos hemócitos no $13^{\circ}$ dia, aumentando para $14,19 \%$ no $14^{\circ}$ dia; a partir deste momento, o número de PR diminuiu, até não ser mais detectado, a partir do $21^{\circ}$ dia, nas nossas condições de observação. Os ES foram as células que sofreram maiores flutuações ao longo do período estudado; existiu 
inicialmente uma elevação na percentagem dos ES até o $17^{\circ}$ dia, com queda posterior, para alcançar um novo pico de $32,97 \%$ no $22^{\circ}$ dia, seguido de queda acentuada, para $17,86 \%$, no $25^{\circ}$ dia. Os PL foram os hemócitos detectados em maior número nas larvas jovens, representando $36,69 \%$ dos hemócitos no $13^{\circ}$ dia. Ao longo do período estudado, houve uma diminuição gradativa no número de PL, representando $19,54 \%$ dos hemócitos no $26^{\circ}$ dia. Deve-se ressaltar que houve, no $19^{\circ}$ dia, uma elevação transitória na percentagem dos PL, quando representavam $32,80 \%$ dos hemócitos circulantes. Os GR foram o segundo tipo mais encontrado no início do período estudado, apresentando um aumento progressivo no seu número, ao longo do desenvolvimento larval, alcançando o pico de $49,65 \%$ em larvas com 26 dias.

Tabela II. Contagem diferencial de hemócitos $(C D H)$ em hemolinfa de larvas de $D$. saccharalis, com idade variando de 13 a 26 dias.

\begin{tabular}{|c|c|c|c|c|c|c|c|c|c|c|c|c|c|}
\hline \multirow{3}{*}{$\begin{array}{l}\text { Idade } \\
\text { larval } \\
\text { (dias) }\end{array}$} & \multicolumn{12}{|c|}{ Tipos celulares } & \multirow{3}{*}{$\begin{array}{l}\text { Total de } \\
\text { hemócito } \\
\text { contados }\end{array}$} \\
\hline & \multicolumn{2}{|c|}{ PR } & \multicolumn{2}{|c|}{$V E$} & \multicolumn{2}{|c|}{$\mathrm{PL}$} & \multicolumn{2}{|c|}{$G R$} & \multicolumn{2}{|c|}{ ES } & \multicolumn{2}{|c|}{$O E$} & \\
\hline & $\mathrm{n}$ & $\%$ & $n$ & $\%$ & $n$ & $\%$ & $n$ & $\%$ & $n$ & $\%$ & $n$ & $\%$ & \\
\hline 13 & 106 & 10.57 & 64 & 6.38 & 368 & 36,69 & 265 & 26,42 & 169 & 16.85 & 31 & 3.09 & 1003 \\
\hline 14 & 142 & 14,19 & 63 & 6,29 & 359 & 35,86 & 218 & 21,78 & 191 & 19.08 & 28 & 2.80 & 1001 \\
\hline 15 & 111 & 11.09 & 83 & 8.29 & 311 & 31,07 & 227 & 22.68 & 228 & 22.78 & 41 & 4.10 & 1001 \\
\hline 16 & 62 & 6,19 & 102 & 10,18 & 273 & 27.25 & 285 & 28,44 & 231 & 23,05 & 49 & 4,89 & 1002 \\
\hline 17 & 39 & 3,90 & 90 & 8.99 & 274 & 27,37 & 277 & 27.67 & 278 & 27,77 & 43 & 4,30 & 1001 \\
\hline 18 & 16 & 1.60 & 90 & 9.00 & 280 & 28.00 & 357 & 35.70 & 219 & 21.90 & 38 & 3.80 & 1000 \\
\hline 19 & 10 & 1.00 & 77 & 7,70 & 328 & 32,80 & 331 & 33,10 & 214 & 21.40 & 40 & 4,00 & 1000 \\
\hline 20 & 4 & 0,40 & 73 & 7,30 & 295 & 29,50 & 307 & 30,70 & 283 & 28,30 & 38 & 3,80 & 1000 \\
\hline 21 & 0 & 0,00 & 86 & 8,60 & 238 & 23,80 & 326 & 32,60 & 331 & 33,10 & 29 & 2.90 & 1000 \\
\hline 22 & 0 & 0,00 & 97 & 9,69 & 202 & 20,18 & 338 & 33.77 & 330 & 32,97 & 34 & 3,40 & 1001 \\
\hline 23 & 0 & 0,00 & 78 & 7,80 & 205 & 20,50 & 338 & 33,80 & 327 & 32,70 & 52 & 5,20 & 1000 \\
\hline 24 & 0 & 0,00 & 77 & 7,69 & 257 & 25,67 & 422 & 42,16 & 195 & 19,48 & 50 & 5,00 & 1001 \\
\hline 25 & 0 & 0,00 & 72 & 7,19 & 243 & 24,25 & 447 & 44,61 & 179 & 17,86 & 61 & 6.09 & 1002 \\
\hline 26 & 0 & 0,00 & 70 & 6,98 & 196 & 19,54 & 498 & 49,65 & 204 & 20,34 & 35 & 3,49 & 1003 \\
\hline
\end{tabular}

* (n) Número de células, (\%) percentagem do tipo celular em relação à população total de hemócitos, (PR) prohemócito, (VE) vermiforme, (PL) plasmatócito, (GR) granulócito, (ES) esferulócito, (OE) oenocitóide.

\section{DISCUSSÃO}

Seis tipos de hemócitos foram caracterizados morfologicamente em hemolinfa de larvas de $D$. saccharalis, quando analisada em microscópio de contraste de fase: prohemócito (PR), plasmátocito (PL), granulócito (GR), esferulócito (ES), oenocitóide (OE) e célula vermiforme (VE). Nossos resultados estão parcialmente em concordância com os obtidos por BARDUCO et al. (1988), no mesmo inseto, embora estes autores tenham se utilizados de técnica diferente na preparação da hemolinfa (esfregaços fixados e corados). Os referidos autores encontraram seis tipos de hemócitos, sendo que os PR, PL, GR, ES e OE foram coincidentes, na sua descrição morfológica, aos por nós observados; identificaram 

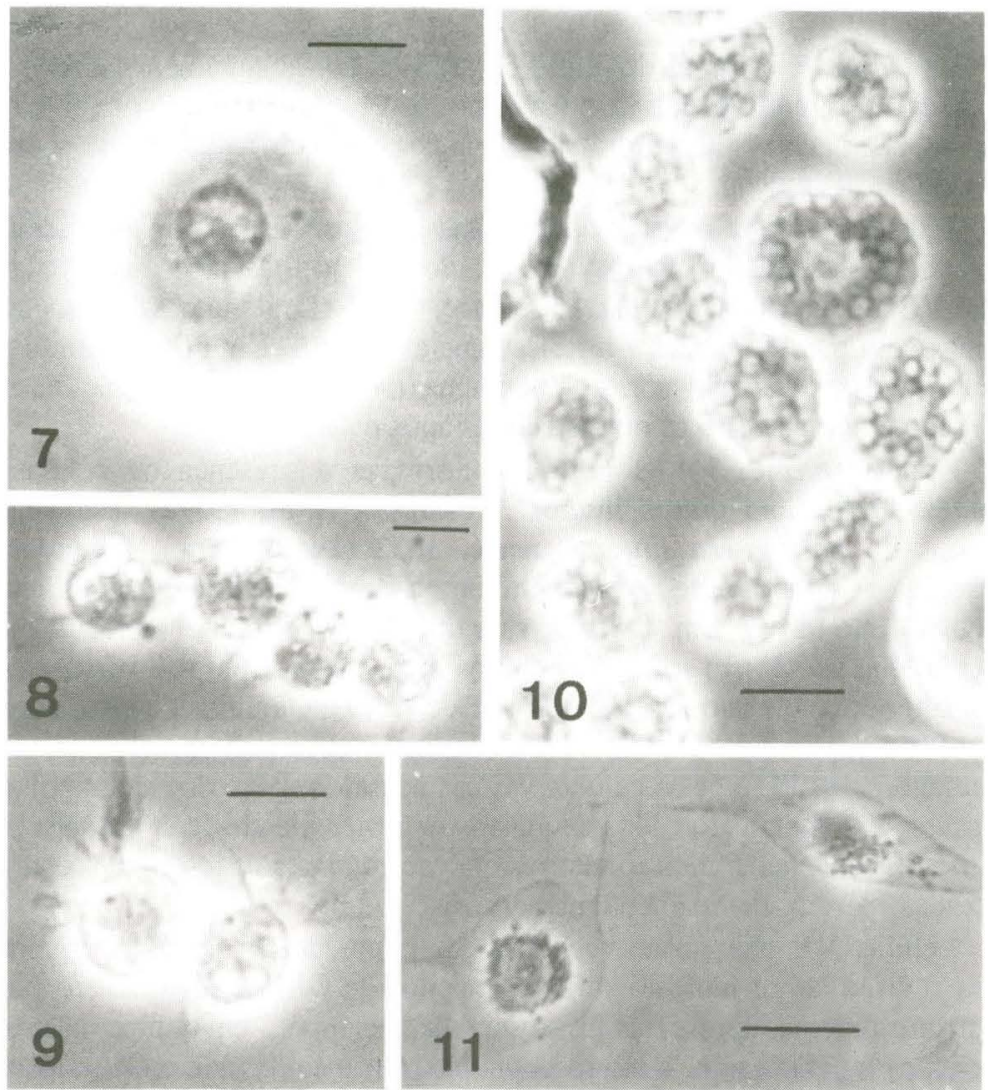

Figs 7-11. Hemócitos de larvas de $D$. saccharalis. (7) $\mathrm{OE}$ em larvas de 22 dias (barra=

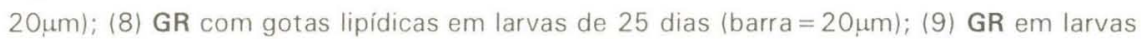
de 23 dias (barra $=20 \mu \mathrm{m}$ ); (10) ES em larvas de 17 dias (barra $=30 \mu \mathrm{m}$ ); (1 1) PL espalhados, em larvas de 19 dias (barra $=50 \mu \mathrm{m})$. Prohemócito (PR), Plasmatócito (PL), Granulócito (GR), Esferulócito (ES), Oenocitóide (OE), Células Vermiformes (VE).

o adipohemócitos $(\mathrm{AD})$, como sendo seu sexto tipo celular, não reconhecendo as células VE na hemolinfa de $D$. saccharalis.

Os AD, identificados por BARDUCO et al. (1988) principalmente em larvas próximas à pupação, foram considerados, em nossas observações, como sendo GR que acumularam gotículas de lipídio em seu citoplasma. Este acúmulo de lípidios em GR foi relatado por diversos autores em diferentes insetos (WIGGLESWORTH 1959; Price \& RatclifFe 1974; KaAya \& RatClifFe 1982; Gupta 1985; RATCLIFFE et al. 1985; entre outros). A análise ultraestrutural dos hemócitos de D. saccharalis (TOLEDO \& GREGÓRIO 1983) mostrou que o chamado AD era célula indistinguível do GR, porém com gotas lipídicas, corroborando nossas observações quanto à inexistência de tipo celular caracterizável como $\mathrm{AD}$ em larvas deste inseto. 
As células VE foram de difícil caracterização e inicialmente identificadas como sendo "PL modificado": a morfologia dos PL e VE era bastante semelhante, porém os chamados "PL modificados" nunca aderiam à lâmina de vidro, ao contrário dos PL típicos.

A distinção entre os PL e as chamadas células VE não tem sido aceita por muitos pesquisadores, em vários insetos. Porém, Jones (1959) já apontava as células VE de larva de Prodenia Gueneé, 1852 (Lepidoptera) como células parecidas com aos PL, embora referisse que as VE diferiam dos PL em diversas particularidades: elas não sofriam nenhuma modificação na forma durante a observação e não aderiam às outras células após o sangramento.

Posteriormente, JONES (1962) confirmava a presença de células VE, diferentes de PL, em outros insetos. KuRIHARA et al. (1992), estudando os hemócitos de Spodoptera litura Gueneé, 1852 (Lepidoptera: Noctuidae) em microscopia de contraste de fase, identificaram claramente as células VE entre os hemócitos deste inseto. Em S. litura, este tipo celular diferia completamente dos PL, sendo que as VE não sofriam nenhuma mudança morfológica vários minutos após o sangramento e não aderiam às outras células ou lâmina de vidro, enquanto que os PL espalhavam-se e aderiam à lâmina. Comportamento semelhante foi apresentado pelos PL e pelas células VE nas nossas preparações de hemolinfa de D. saccharalis, apontando cada vez mais para a necessidade de se caracterizar os diferentes tipos de hemócitos ao microscópio de contraste de fase, em preparações não fixadas, porém, devidamente preservadas.

Células VE não foram reconhecidas como um tipo celular distinto na extensa revisão sobre morfologia de hemócitos de GUPTA (1985), isto porque, ultraestruturalmente, apresentavam-se semelhante aos PL, em muitos insetos. Em D. saccharalis, entretanto, a microscopia eletrônica confirmou a diversidade dos PL e das células VE (TOLEdo \& GREGório 1983). Estes autores mostraram claramente que as características ultraestruturais citoplasmáticas dos PL e VE eram bastante distintas.

Os outros tipos celulares encontrados em hemolinfa de larvas de $D$. saccharalis (PR, PL, GR, ES e OE) apresentaram morfologia coincidente à relatada na literatura por vários autores (GUPTA 1985; RATCLIFFE 1986; BARDUCO et al. 1988; KURIHARA et al. 1992; entre outras).

O estudo quantitativo da hemolinfa de $D$. saccharalis mostrou que o número total de hemócitos circulantes não apresentou grandes variações, ao longo do período estudado. BARDUCO et al. (1988), analisando a hemolinfa do mesmo inseto, também constataram que a contagem total de hemócitos (CTH) variou pouco ao longo do desenvolvimento larval. Entretanto, detectaram um aumento pronunciado na $\mathrm{CTH}$ no $23^{\circ}$ dia, discordando assim dos resultados aqui apresentados; além disso, a média dos valores aqui obtida para a CTH diferiu da daqueles autores. Nas condiçōes utilizadas por BARDUCO et al. (1988), que utilizaram hemolinfa diluída quantificada em contador automático de células Coultner $\mathrm{D}_{2}$, os valores obtidos foram menores que os aqui encontrados, em hemolinfa de $D$. saccharalis não diluída, quantificada em câmara de Neubauer modificada. Essa 
diferença pode ser atribuída à fragilidade dos hemócitos, que provavelmente degranularam e/ou coagularam durante a manipulação no contador automático e/ou em contato com a solução diluente, não adequada para a sua preservação.

A contagem diferencial de hemócitos $(\mathrm{CDH})$ em $D$. saccharalis mostrou que todos os tipos celulares foram detectados ao longo do desenvolvimento larval, exceto os PR, que só puderam ser observados no início do período estudado.

Os OE e VE foram os tipos menos encontrados, mostrando poucas variações ao longo do período analisado. Com relação aos OE, observações semelhantes quanto à sua baixa frequência foram obtidas em Bombyx Schrank, 1801 (NITTONO 1960), em Hyalophora Ducan, 1841 (LEA \& GILBERT 1966), em Pieris Schrank, 1801 (TAKADA \& KiTANO 1971), em Euxoa Hübner, 1822 (ARNOLD \& HinkS 1976), todos Lepidoptera, bem como em D. saccharalis (BARDUCO et al. 1988), entre outras. Como as VE nem sempre foram identificadas em todos os insetos estudados, torna-se difícil a comparação dos nossos resultados quantitativos com os dados da literatura. Kurihara et al. (1992) encontraram que as VE representavam entre 1,9 - 6,7\% da população de hemócitos de $S$. litura; resultados semelhantes foram obtidos por AHMAD (1993), no mesmo inseto. Os resultados obtidos mostraram que em $D$. saccharalis, as VE representaram de 6,28-10,18\% dos hemócitos circulantes.

Os PR foram mais freqüentes que os $\mathrm{OE}$ e $\mathrm{VE}$, no início das nossas observações, chegando a representar 14,19\% dos hemócitos circulantes em larvas de 14 dias, diminuíndo em número até não serem mais detectados em larvas com 21 dias, nas nossas condições experimentais. Estes resultados são discordantes dos encontrados por BARDUCO et al. (1988), que apontaram o PR como a célula menos encontrada durante o período larval, detectáveis somente a partir do $20^{\circ}$ dia de desenvolvimento da broca da cana. GuPTA (1979) relatou que os PR seriam mais numerosos nos estágios iniciais de desenvolvimento larval, sendo este fato bastante aceito, para a maioria dos insetos. ARNOLD \& HINKS (1976), estudando larvas de Euxoa, mostraram uma frequência de $6 \%$ para os PR, sendo este resultados contestado por KAAYA \& RATCLIFFE (1982), que acreditavam terem sido incluídos, neste valor, os chamados PL jovens, que são muitas vezes indistinguíveis dos $\mathrm{PR}$.

Os PL, nas observações, foram as células mais numerosas no início do período estudado ( $13^{\circ}$ dia $-36,69 \%$ ), diminuíndo gradativamente até o final das observações $\left(26^{\circ}\right.$ dia $\left.-19,54 \%\right)$. BARDuCo et al. (1988), no mesmo inseto, observaram frequência bem maiores que as dos PL (67,67\% aos 13 dias); uma vez que os referidos autores utilizaram-se de esfregaços corados de hemolinfa, podem ter ocorrido modificações na morfologia celular que induziram os autores a contabilizarem os PR como PL, uma vez que não conseguiram detectar PR nas larvas jovens, contrariando os dados da literatura.

Os ES foram o terceiro tipo mais numeroso entre as células sanguíneas de larvas de $D$. saccharalis. Esta células, embora mostrassem flutuações no seu número, ao longo do desenvolvimento larval, apresentaram um aumento progressivo com dois picos, quando representavam 27,77 e $33,10 \%$ aos 17 e 21 dias, 
respectivamente; posteriormente, diminuíram a valores próximos aos encontrados no início das observações. Os resultados discordam dos obtidos por BARDUCO et al. (1988), que detectaram flutuações extremas deste tipo celular, no decorrer do desenvolvimento larval da broca da cana. Novamente credita-se esta discrepância de resultados, para o mesmo inseto, às diferentes metodologias utilizadas na preparação dos hemócitos. NitTono (1960) analisando a hemolinfa de larvas de Bombyx mori Linnaeus, 1758 em jejum, constatou que os ES representavam 50\% da população celular. SDIRC \& GLOOR (1979) em hemolinfa de Drosophila Fallen, 1823, observaram que os ES aumentavam em número com o desenvolvimento larval, atingindo um pico 24 horas antes da metamorfose, quando então decresciam rapidamente até quase zero, não sendo mais observados em pré-pupas. Em S. litura os ES também diminuíram em número nas larvas próximas à pupação, como observado por KURIHARA et al. (1992), corroborando nossos achados.

Os GR foram o segundo tipo celular mais numeroso em larvas de $D$. saccharalis, durante o período por nós estudado, apresentando aumento progressivo e representando $49,65 \%$ dos hemócitos em larvas com 26 dias. NiTTONO (1960) observou em B. mori que a frequência dos GR também aumentou progressivamente, por ocasião do último instar larval. Já em Galleria mellonella Treitschke, 1830, SHAPIRO (1979) constatou que, após um aumento dos GR no início do último instar larval, sua percentagem na população de hemócitos permanecia alta e constante. Em S. litura, KURIHARA et al. (1992) relataram que o GR foi o tipo celular mais frequente na hemolinfa deste inseto, representando de 37 a $47 \%$ dos hemócitos circulantes.BARDUCO et al. (1988), entretanto, relataram que os GR apresentaram grandes flutuações, com pico em broca da cana com 21 dias de desenvolvimento, seguido então de queda acentuada; atribui-se esta discrepância de resultados às condições de preparação de esfregaço utilizadas por estes autores, que devem ter dificultado a identificação segura dos GR, por serem células frágeis e que perdem o conteúdo de seus grânulos com facilidade.

A análise dos nossos resultados mostraram comportamentos antagônicos quanto à $\mathrm{CDH}$, entre $\mathrm{PR}$ e PL e entre PL e GR, sugerindo que o PR possa se diferenciar em PL, que se transformaria em GR. Imagens sugestivas de formas intermediárias entre PR e PL foram observadas, evidenciando morfologicamente a transformação sugerida pela $\mathrm{CDH}$. Entretanto, não observou-se hemócitos com características morfológicas intermediárias entre PL e GR. Há necessidade de outros estudos, com técnicas diferentes, para comprovar ou mesmo sugerir linhas de diferenciação entre os diferentes tipos de hemócitos.

Baseado nos resultados, pode-se concluir que durante o desenvolvimento larval de $D$. saccharalis, o número total de hemócitos bem como a morfologia destas células não mostram modificações significativas. Entretanto, a percentagem de cada um dos tipos de hemócitos, em relação à população total das células sanguíneas circulantes, modifica-se com o desenvolvimento das larvas. O significado funcional desta variação na capacidade do inseto em reagir contra elementos estranhos deverá ser avaliado. 
AGRADECIMENTOS. Os autores agradecem ao Laboratório de Controle de Pragas da Usina da Barra Açúcar e Álcool S.A., pelo fornecimento das larvas e do meio de cultura, utilizados para a realização deste trabalho.

\section{REFERÊNCIAS BIBLIOGRÁFICAS}

AHmAD, A. 1993. Effect of $\beta$-ecdysone ingestion on total and differential haemocyte counts (THC \& DHC) in the tobacco caterpillar, Spodoptera litura Fabr. (Lepidoptera: Noctuidae). Bull. Soc. Ent. 66: 113-122.

ARnOLD, J.W. \& H. HinkS. 1976. Haemopoiesis in Lepidoptera. I. The multiplication of circulating haemocytes. Can. Jour. Zool. 54: 1003-1012.

Azambuja, P.; E.S. Garcia \& N.A. Ratcliffe. 1991. Aspects of classification of Hemiptera hemocytes from six Triatomine species. Mem. Inst. Oswaldo Cruz. 86: 1-10.

Barduco, M.C.; E.A. Gregório \& L.A. Toledo. 1988. Hemócitos de Diatraea saccharalis (Lepidoptera: Pyralidae) no período larval. Estudo morfológico e quantitativo. Rev. Bras. Biol. 48: 925-932.

Beaulaton, J. 1968. La tunica propria et ses relations avec les fibres conjunctives et les hémocytes. Jour. Ultrastruct. Res. 23: 474-498.

BOHN, H. 1986. Hemolymph clotting in insects, p.188-207. In: M. BREHÉLIN (Ed.). Immunity Invertebrates. New York, Spring-Verlag, 233p.

Chiang, A.S.; A.P. Gupta \& S.S. Han. 1988. Arthropod immune system: I. Comparative light and electron microscopic accounts of immunocytes and other hemocytes of Blattella germanica (Dictyoptera : Blattellidae). Jour. Morphol. 198: 257-267.

Costa-Neto, P.L.O. 1984. Estatística. São Paulo, Editora Blucher, 264p.

DE Kort, C.A. \& N.A. Granger. 1981. Regulation of the juvenile hormone titer. Ann. Rev. Ent. 26: 1-28.

Gotz, P. \& H.G. Boman. 1985. Insect immunity, p.454-485. In: G.A.Kertut \& L.I. GILBERT (Eds). Comprehensive insect physiology, biochemistry and pharmacology. Oxford, Pergamon Press, vol. 3., 625p.

GuptA, A.P. 1979. Hemocyte types; their structures, synonymies, interrelationships and taxonomic significance, p.85-127. In: A.P. GUPTA (Ed.). Insect hemocytes: development, forms, functions and techniques. Cambridge, Cambridge University Press, 614p.

1985. Cellular elements in the hemolymph, p. 402-444. In: G.A. Kertut \& L.I. Gilbert (Eds). Comprehensive insect physiology, biochemistry and pharmacology. Oxford, Pergamon Press, vol. 3., 625p.

HENSLEY, S.D. \& A. M. JR. HAMMOND. 1968. Laboratory techniques for rearing the sugarcane borer on an artificial diet. Jour. Entomol. 61: 1742-1743.

JONES, J.C. 1959. A phase contrast study of the blood-cells in Prodenia larvae (Order Lepidoptera). Q. Jour. Microscop. Sci. 100: 17-23.

1962. Current concepts concerning insect hemocytes. Amer. Jour. Zool. 2: 209-246. 
KAAYA, G.P. \& N.A. RATClifFe. 1982. Comparative study of hemocytes and associated cells of some medically important dipterans. Jour. Morphol. 173: 351-365.

Kurihara, Y.; T. Shimazut \& H. Wago. 1992. Classification of hemocytes in the common cutworm, Spodoptera litura (Lepidoptera: Noctuidae) I. Phase microscopic study. Appl. Entomol. Zool. 27: 225-235.

LEA, M.S. \& L.I. GilberT. 1966. The haemocytes of Hyalophora cecropia (Lepidoptera). Jour. Morphol. 118: 197-216.

Leonard, C.M.; K. Soderhall \& N.A. Ratcliffe. 1985. Studies of prophenoloxidase and protease of Blaberus craniifer haemocytes. Insect Biochem. 15: 803-810.

NitTono, Y. 1960. Studies on the blood cells in the silkworm Bombyx mori L. Bull. Seric. Exp. Stn. 16: 171-266.

PERCY, J. 1978. Haemocytes associated with basement membrane of sex pheromone gland of Trichoplusia ni (Lepidoptera: Noctuidae). Ultrastructural observations. Canad. Jour. Zool. 56: 238-245.

PRICE, C.D. \& N.A RATClifFE. 1974. A reappraisal of insect haemocyte classification by the examination of blood from fifteen insect orders. Z . Zellforsch. Mikrosk. Anat. 147: 537-549.

RATCLIFFE, N.A. 1986. Insect cellular immunity and the recognition of foreigness, p.21-43. In: A.M. LACKIE (Ed.). Immune mechanism in invertebrate vectors. Oxford, Claredon Press, 285p.

RAtClifFe, N.A. \& A.F. Rowley. 1979. Role of hemocytes in defense against biological agents, p. 331-414. In: A.P. GUPTA (Ed.). Insect hemocytes: development, forms, functions and techniques. Cambridge, Cambridge University Press, 614p.

Ratcliffe, N.A.; A.F. Rowley; S.W. Fitzgerald \& C.P. Rhodes. 1985. Invertebrate immunity: basic concepts and recent advances. Int. Rev. Cytol. 97: 183-349.

SAXENA, B.P. 1992. Comparative study of haemocytes of three lepidopterans by light and scanning electron microscopy. Acta Entomol. Bohemoslov. 89: 323-339.

SECCO, V.N.D.P. 1990. Ultra-estrutura do desenvolvimento do ovário de Dermatobia hominis (Diptera: Cuterebridae). Dissertação de Mestrado, não publicada, Instituto de Biociências, Universidade Estadual Paulista, Botucatu, $71 \mathrm{p}$.

SHAPIRO, M. 1979. Changes in the hemocyte population, p.475-523. In: A.P. GUPTA (Ed.). Insect hemocytes: development, forms, functions and techniques. Cambridge, Cambridge University Press, 614p.

Srdic, Z. \& H. Gloor. 1979. Spherulle cells in Drosophila species. Experientia. 35: 1246-1249.

TAKADA, M. \& H. KitTANo. 1971. Studies on the larval hemocytes in the cabbage with butterfly, Pieris rapae crucivora (Boisduval), with special reference to hemocyte classifications, phagocytic activity and encapsulative capacity. 
Kontyú. 39: 385-394.

TAKEDA, N. 1977. Brain hormone carrier haemocytes in the moth Monema flavescens. Jour. Insect Physiol. 23: 1245-1254.

TOLEDO, L.A. \& E.A. GREGÓRIO. 1983. Ultraestrutura dos hemócitos de larvas de Diatraea saccharalis (Lepidoptera: Pyralidae). Resumos do III Congresso Brasileiro de Biologia Celular, São Paulo, p.47.

Vieira, S. \& R. Hoffmann. 1988. Elementos de Estatística. São Paulo, Editora Atlas, 159p.

Wigglesworth, V.B. 1959. Insect blood cells. Ann. Rev. Entomol. 4: 1-16. 1972. Haemocytes and basement membrane formation in Rhodnius. Jour. Insect Physiol. 19: 831-844.

1979a. Hemocytes and growth in insects, p.303-318. In: A.P. GUPTA (Ed.). Insect hemocytes: development, forms, functions and techniques. Cambridge, Cambridge University Press, 614p.

$1979 \mathrm{~b}$. Secretory activities of plasmatocytes and oenocytoids during the moulting cycle in an insect (Rhodnius). Tissue Cell. 11: 69-78. 